\title{
FRUIT AND VEGETABLE HANDLING PRACTICES AND A QUALITATIVE STUDY ON PESTICIDE RESIDUES IN MALAYSIA
}

\author{
BOON TSANN LIM ${ }^{1}$, WYE HONG LEONG ${ }^{1}$, SHU YI TEH ${ }^{1}$, ZABIDI ZABIDI-HUSSIN ${ }^{2}$, \\ THIYAGAR NADARAJAW ${ }^{3}$, SATHIYA MARAN ${ }^{4}, \mathrm{KOK} \mathrm{SONG} \mathrm{LAI}^{5}, \mathrm{CHUN}^{2}$ WIE CHONG ${ }^{4}$, \\ SWEE YEE CHIN ${ }^{6}$ and SWEE HUA ERIN LIM ${ }^{5 *}$ \\ ${ }^{1}$ Perdana University-Royal College of Surgeons in Ireland, \\ 43400 Serdang, Selangor, Malaysia \\ ${ }^{2}$ School of Medicine, International Medical University, Bukit Jalil, \\ 57000 Kuala Lumpur, Malaysia \\ ${ }^{3}$ Department of Paediatrics, Hospital Sultanah Bahiyah, 05460, \\ Alor Setar, Kedah, Malaysia \\ ${ }^{4}$ School of Pharmacy, Monash University Malaysia, Jalan Lagoon Selatan, \\ 47500 Bandar Sunway, Selangor Darul Ehsan, Malaysia \\ ${ }^{5}$ Health Science Division, Abu Dhabi Women's College, Higher Colleges of Technology, \\ 41012 Abu Dhabi, UAE \\ ${ }^{6}$ Department of Pharmaceutical Chemistry, School of Pharmacy, International Medical University, \\ Bukit Jalil, 57000 Kuala Lumpur, Malaysia \\ *E-mail: erinlimsh@gmail.com,lerin@hct.ac.ae
}

Accepted 25 April 2021, Published online 15 May 2021

The increasing demand for fruits and vegetables has unfortunately led to increased use of pesticides, especially in crop protection to increase yield (Tsagkaris et al., 2021). Regardless of the guidelines by the World Health Organization (WHO), any amount of pesticide residues in produce is reported to lead to toxicity (Tsagkaris et al., 2021). Studies have reported that humans are exposed to pesticides through various routes such as dermal contact, ingestion, inhalation, etc (Zaidon et al., 2018). Oral ingestion of pesticide-contaminated fruits and vegetables has been reported as the main route of exposure in the general human population (Reeves et al., 2019). The adverse effects due to pesticide ingestion in humans range from short-term effects like nausea and headache to chronic effects such as birth defects, infertility, immunological effects, and cancer (Cecchi et al., 2012; Alavanja et al., 2013). Recent research suggests that even low levels of pesticide exposure can affect young children's neurological and behavioral development, neonatal reflexes, psychomotor and mental development, and induce attention-deficit hyperactivity disorder (Liu \& Schelar, 2012). Furthermore, pediatric cancers have also been linked to pesticide exposure (Health, 2012).

\footnotetext{
* To whom correspondence should be addressed.
}

In early 1990, the World Health Organization (WHO) estimated about one million unintentional pesticide poisonings occur, causing about 20,000 deaths yearly (Boedeker et al., 2020), while the average incidence of pesticide ingestion in Malaysia was reported to be 3.8 per 100000 population (Azzalia et al., 2020). A recent study investigating the presence of pesticides residues in fruits and vegetables reported that peach $(88 \%)$, dill $(84 \%)$, mushroom (83\%), arugula (73\%), and spinach $(72 \%)$ were the crops with the highest percentages of pesticide residues (Toptanci et al., 2021). Another study reported that the levels of pesticide residues detected in fruits and vegetables in Nigeria were above the UK/European Commission Maximum Residue Limits (MRLs) scoring between 25\% to $100 \%$ (Odewale et al., 2021). In Malaysia, the percentages of pesticides above MRL set by EU was detected in lettuce $(13.3 \%)$, broccoli $(10 \%)$, spinach $(8.3 \%)$, mustard $(6.6 \%)$, cauliflower $(4.5 \%)$, cabbage $(4 \%)$ (Farina et al., 2017). Despite these findings, the exact reason for the high level of pesticides in fruits and vegetables remains vague and the possible effect of handling practices is being questioned. Therefore, this study sets out to determine the presence of eight common pesticides in eaten raw fruits and vegetables; lettuce, tomato, strawberry, and guava from selected urban, suburban, and rural markets in Klang Valley, 
Selangor, Malaysia. Furthermore, the fruits and vegetables handling practices of the retailers were also investigated using a cross-sectional survey, in linking the presence of pesticides with produce handling practices.

In this study, a total of 44 samples with approximately $200 \mathrm{~g}$ each were examined. The sampling was carried out in June 2017 and according to the retailers, these fresh fruits and vegetables were sourced from Cameron Highlands and Thailand. Upon collection, these fresh produces were transported to the laboratory and kept in the refrigerator at $4^{\circ} \mathrm{C}$ to be processed the following day. Sample extraction was conducted by the method adopted by Ferrer et al. (2005). In brief, $15 \mathrm{~g}$ of the samples were weighed and homogenized. The homogenized samples were blended with $1 \mathrm{~mL}$ of sodium hydroxide and $90 \mathrm{~mL}$ of ethyl acetate for $30 \mathrm{~s}$. The extract was then centrifuged for $5 \mathrm{~min}$ at 3000 r.p.m. and the supernatant filtered through $20 \mathrm{~g}$ anhydrous sodium sulfate to remove excess water. The remaining solid was then washed again with $50 \mathrm{~mL}$ of ethyl acetate before concentrating with a vacuum rotary evaporator. A total of $15 \mathrm{~mL}$ of methanol was used to dissolve the final residue through sonication.

A total of eight pesticide reference standards; Acetamiprid, Malathion, Iprodione, Dicofol, Chlorpyrifos, Propargite, Propamocarb, and Dimethoate were used in this study. Standard pesticide mix $\left(1 \mathrm{mg} \mathrm{mL}^{-1}\right)$ stock solutions were prepared in toluene and acetonitrile for GC-MS analysis. Gas Chromatography-Mass Spectrometry (GC-MS) using GCMS-TQ8030 Shimadzu was carried out to determine qualitative residues of pesticides in each production. A $1-30 \mathrm{~m} \times 0.25$ or $0.32 \mathrm{~mm}$ ID fused silica capillary column chemically bonded with SE54 (DB-5 or equivalent) and with a film thickness of $1 \mu \mathrm{m}$ was used. The carrier gas used was Helium with a gas pressure of $16 \mathrm{psi}$. The injector temperature was set at $225^{\circ} \mathrm{C}$, while the detector temperature was set at $300^{\circ} \mathrm{C}$. The analysis was carried out with an initial temperature of $100^{\circ} \mathrm{C}$, then held for 2 min under the program of $100^{\circ} \mathrm{C}$ to $160^{\circ} \mathrm{C}$ at $15^{\circ} \mathrm{C} / \mathrm{min}$, and followed by a final temperature of $160^{\circ} \mathrm{C}$ to $270^{\circ} \mathrm{C}$ at $5^{\circ} \mathrm{C} / \mathrm{min}$.

A structured questionnaire, modified from Bajwa and Sandhu (2014) was used to determine the effect of handling and processing on the produce. The questionnaire consists of both close and open-ended questions that evaluate: 1) retailers' demographic data; 2$)$ retailers' handling and processing practices; 3) details on how and where the fruits and vegetables were obtained from, and 4) methods and geographical details of farming. Data analysis was performed using IBM SPSS Version 25 and the chi-square test was used to test significance between variables with $p<0.05$ is considered significant.
This study provides evidence for the presence of pesticides in commonly eaten raw fruits and vegetables in Malaysia. A total of 15 samples (34.1\%) were found to be positive for pesticide residue, while the remaining 29 samples $(65.9 \%)$ were below the detection limit. All the 15 samples showed the presence of Acetamiprid (Figure 1) and of these samples, $43.8 \%$ were from semi-urban markets, while $25 \%$ were from the urban and rural markets (Table 1). Acetamiprid was found most in lettuce $(66.7 \%)$ followed by strawberry (25\%), tomato $(25 \%)$, and guava $(8.33 \%)$. Furthermore, lettuce samples from all the markets make up the highest percentage of pesticide residue detected (66.7\%), despite lettuce having the highest percentage $(66.7 \%)$ to be washed with water before display (Table 2). However, no significant difference $(p=0.669)$ was observed in pesticide residues on lettuce between washing and non-washing practices for lettuce. This is my findings from $\mathrm{Wu}$ and colleagues (2019), who reported that it is difficult to remove pesticides from leafy vegetables using tap water. Furthermore, Chung et al. (2018) also reported that washing and soaking can only reduce the residue' level to a certain degree, while other methods such as blanching, peeling, and soaking in chemical baths are required to properly remove pesticide residue from the surface of fresh fruits and vegetables.

The identification of Acetamiprid in the samples might indicate the extensive use of it in the Malaysian market, especially in semi-urban markets. This might be due to the washing practices of the retailer, whereby a larger number of urban markets retailers washed their fruits and vegetables before placing them on display $(81.3 \%)$, compared to semi-urban (50\%) and rural markets (58.3\%). Previous studies have also reported the presence of Acetamiprid in apples and tomatoes which are also eaten raw (Wijaya et al., 2014; Rasolonjatovo et al., 2017). It is noteworthy that the use of acetamiprid is banned in many countries, because of the severe environmental pollution and pesticide resistance. Apostolou (2020) reported that excessive and improper usages have caused heavy pesticide residues in grains, agricultural products, or food, which could explain the presence of lettuce in the current study.

Studies on a variety of pesticides on produce stored under cool or frozen storage have shown that pesticide residues are stable for months (Yigit \& Velioglu, 2020). This is in line with findings from this study whereby, lettuce which was frequently stored in the chiller $(91.6 \%)$ for $1-5$ days before display harbored the highest percentage of the detected pesticide (Table 3). Conversely, guava which recorded the lowest percentage of pesticide is the least stored in chiller (50\%) for 1 - 5 days. 


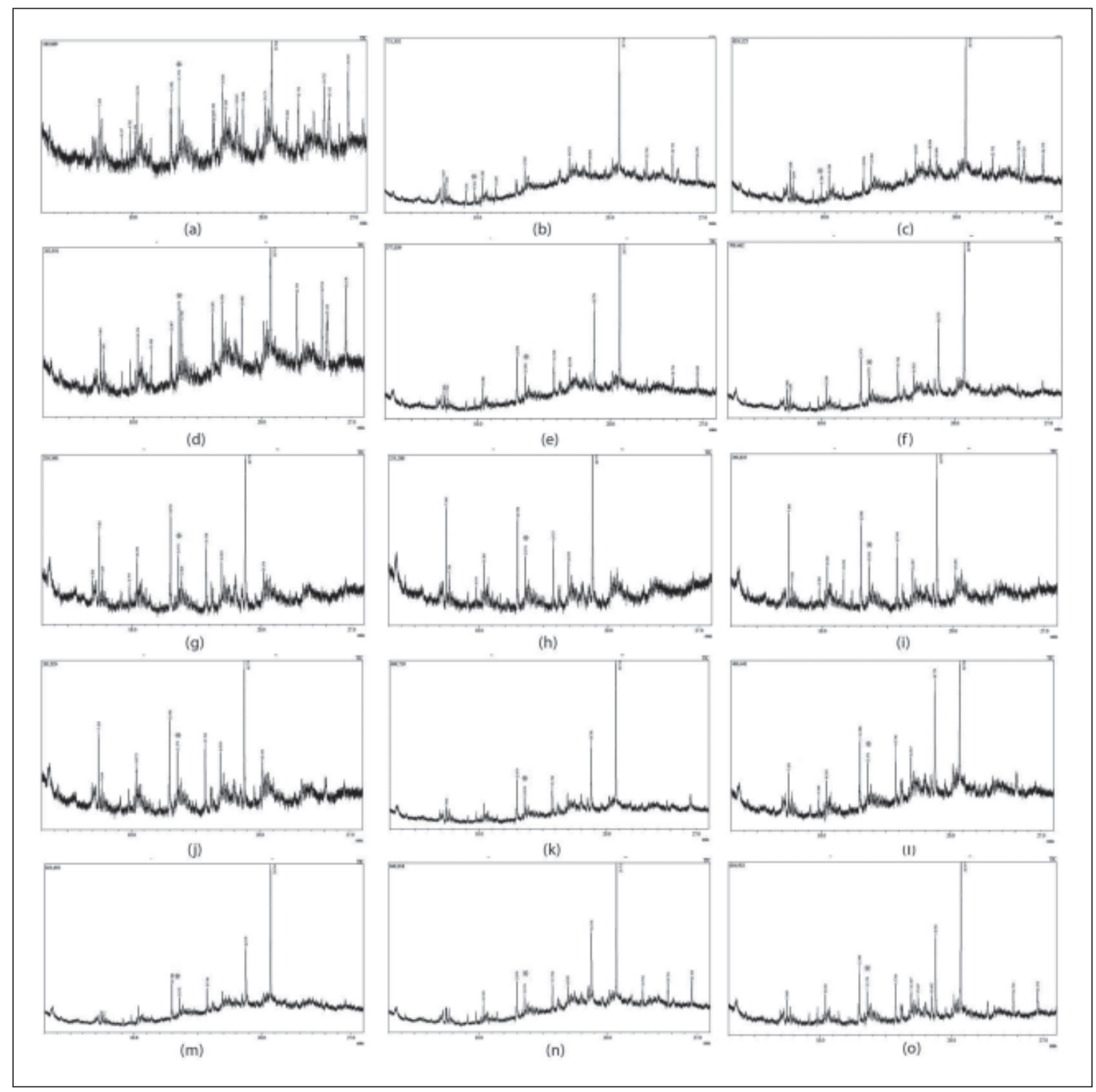

Figure 1. GC-MS Analysis. (a) Urban strawberry. (b) Urban lettuce 1. (c) Urban lettuce 2. (d) Urban tomato. (e) Semi-urban strawberry 1. (f) Semi-urban strawberry 2. (g) Semi-urban lettuce 1. (h) Semi-urban lettuce 2. (i) Semi-urban lettuce 3. (j) Semiurban lettuce 4. (k) Semi-urban tomato. (l) Rural guava. (m) Rural lettuce 1. (n) Rural lettuce 2. (o) Rural tomato. (* indicates the retention time at which eicosane compound was detected in the samples).

Table 1. Pesticide residues in commonly eaten-raw produce from urban, semi-urban, and rural markets

\begin{tabular}{lcccc}
\hline Markets & $\begin{array}{c}\text { Strawberry } \\
(\%)\end{array}$ & $\begin{array}{c}\text { Guava } \\
(\%)\end{array}$ & $\begin{array}{c}\text { Lettuce } \\
(\%)\end{array}$ & $\begin{array}{c}\text { Tomato } \\
(\%)\end{array}$ \\
\hline Urban Markets & 25 & 0 & 50 & 25 \\
Semi-urban Markets & 50 & 0 & 100 & 25 \\
Rural Markets & NA & 25 & 50 & 25 \\
\# Total & $\mathbf{2 5}$ & $\mathbf{8 . 3 3}$ & $\mathbf{6 6 . 7}$ & $\mathbf{2 5}$ \\
\hline
\end{tabular}

NA = Not available because strawberries was not available from the rural market.

\# Total of fruits or vegetables purchased from urban, semi-urban, and rural markets. 
Table 2. Washing of fruits and vegetables before display in urban, semi-urban, and rural markets

\begin{tabular}{lcccc}
\hline Markets & $\begin{array}{c}\text { Strawberry } \\
(\%)\end{array}$ & $\begin{array}{c}\text { Guava } \\
(\%)\end{array}$ & $\begin{array}{c}\text { Lettuce } \\
(\%)\end{array}$ & $\begin{array}{c}\text { Tomato } \\
(\%)\end{array}$ \\
\hline Urban Markets & 75 & 75 & 100 & 75 \\
Semi-urban Markets & 50 & 50 & 50 & 50 \\
Rural Markets & NA & 75 & 50 & 50 \\
\# Total & $\mathbf{4 1 . 7}$ & $\mathbf{6 6 . 7}$ & $\mathbf{6 6 . 7}$ & $\mathbf{5 8 . 3}$ \\
\hline
\end{tabular}

NA = Not available because strawberries was not available from the rural market.

\# Total of fruits or vegetables purchased from urban, semi-urban, and rural markets.

Table 3. Percentage of fruits and vegetable storage in the chiller before display

\begin{tabular}{lcccc}
\hline Markets & $\begin{array}{c}\text { Strawberry } \\
(\%)\end{array}$ & $\begin{array}{c}\text { Guava } \\
(\%)\end{array}$ & $\begin{array}{c}\text { Lettuce } \\
(\%)\end{array}$ & $\begin{array}{c}\text { Tomato } \\
(\%)\end{array}$ \\
\hline Urban Markets & 100 & 25 & 100 & 100 \\
Sem-urban Markets & 100 & 100 & 100 & 100 \\
Rural Markets & NA & 25 & 75 & 50 \\
\# Total & $\mathbf{6 6 . 7}$ & $\mathbf{5 0}$ & $\mathbf{9 1 . 6}$ & $\mathbf{8 3 . 3}$ \\
\hline
\end{tabular}

$\mathrm{NA}=$ Not available because strawberries was not available from the rural market.

\# Total of fruits or vegetables purchased from urban, semi-urban, and rural markets.

This study has investigated the presence of different types of commonly used pesticides in Malaysian markets among commonly eaten raw fruits and vegetables. The findings indicate an evident presence of acetamiprid thus necessitating the importance of regulations to monitor MRL in fruits and vegetables sold to consumers. The findings from this study indicate that washing with water has a very minimal effect to reduce the pesticide residue level and extended storage could lead to degradation of the pesticide, which is detrimental. The findings from this pilot study elucidate the need to further investigate the presence of pesticide residues in more varieties of produce in the Malaysian market on a larger scale.

\section{ACKNOWLEDGEMENT}

The authors are grateful to the Malaysian Paediatric Association Foundation and Advanced Technology Entrepreneur Program (ADAPT), Majlis Amanah Rakyat (MARA) for supporting this study.

\section{SUPPLEMENTARY MATERIALS}

Available at http://www.mabjournal.com/images/ supplementary/11375supp.pdf

\section{REFERENCES}

Alavanja, M.C.R., Ross, M.K. \& Bonner, M.R. 2013. Increased cancer burden among pesticide applicators and others due to pesticide exposure. A Cancer Journal for Clinicians, 63: 120-142.

Apostolou, T., Loizou, K., Hadjilouka, A., Inglezakis, A. \& Kintzios, S. 2020. Newly developed system for acetamiprid residue screening in the lettuce samples based on a bioelectric cell biosensor. Biosensors, 10(2): 8.

Azzalia, K., Leong, Y.-H., Jaafar, M.H., Khan, H., Rani, N., Razali, F. \& Majid, M. 2020. Epidemiology and risk factors of pesticide poisoning in Malaysia: A retrospective analysis by the National Poison Centre (NPC) from 2006 to 2015. BMJ Open, 10(6): e036048.

Bajwa, U. \& Sandhu, K.S. 2014. Effect of handling and processing on pesticide residues in food a review. Journal of Food Science and Technology, 51: 201-220.

Boedeker, W., Watts, M., Clausing, P. \& Marquez, E. 2020. The global distribution of acute unintentional pesticide poisoning: estimations based on a systematic review. BMC Public Health, 20: 1875. 
Cecchi, A., Rovedatti, M.G., Sabino, G. \& Magnarelli, G.G. 2012. Environmental exposure to organophosphate pesticides: assessment of endocrine disruption and hepatotoxicity in pregnant women. Ecotoxicology and Environmental Safety, 80: 280-287.

Chung, S.W. 2018. How effective are common household preparations on removing pesticide residues from fruit and vegetables? A review. Journal of the Science of Food and Agriculture, 98: 2857-2870.

Council on Environmental Heath. 2012. Pesticide exposure in children. Pediatrics, 130(6): e1757e1763.

Farina, Y., Abdullah, M.P., Bibi, N. \& Khalik, W.M.A.W.M. 2017. Determination of pesticide residues in leafy vegetables at parts per billion levels by a chemometric study using GC-ECD in Cameron Highlands, Malaysia. Food Chemistry, 224: 55-61.

Ferrer, I., García-Reyes, J.F., Mezcua, M., Thurman, E.M. \& Fernández-Alba, A.R. 2005. Multi-residue pesticide analysis in fruits and vegetables by liquid chromatography-time-of-flight mass spectrometry. Journal of Chromatography A, 1082: 81-90.

Liu, J. \& Schelar, E. 2012. Pesticide Exposure and Child Neurodevelopment. Workplace Health \& Safety, 60: 235-243.

Odewale, G.O., Sosan, M.B., Oyekunle, J.A.O. \& Adeleye, A.O. 2021. Human health risk assessment of dichlorodiphenyltrichloroethane (DDT) and hexachlorocyclohexane $(\mathrm{HCH})$ pesticide residues in fruits and vegetables in Nigeria. Environmental Science and Pollution Research (2021).

Rasolonjatovo, M.A., Cemek, M., Cengiz, M.F., Ortaç, D., Konuk, H.B., Karaman, E., Kocaman, A.T. \& Göneş, S. 2017. Reduction of methomyl and acetamiprid residues from tomatoes after various household washing solutions. International Journal of Food Properties, 20: 2748-2759.
Reeves, W.R., McGuire, M.K., Stokes, M. \& Vicini, J.L. 2019. Assessing the Safety of Pesticides in Food: How Current Regulations Protect Human Health. Advances in Nutrition, 10: 80-88.

Toptanci, İ., Kiralan, M. \& Ramadan, M.F. 2021. Levels of pesticide residues in fruits and vegetables in the Turkish domestic markets. Environmental Science and Pollution Research (2021).

Tsagkaris, A.S., Pulkrabova, J. \& Hajslova, J. 2021. Optical screening methods for pesticide residue detection in food matrices: Advances and emerging analytical trends. Foods, 10(1): 88.

Wijaya, W., Pang, S., Labuza, T.P. \& He, L. 2014. Rapid detection of acetamiprid in foods using surface-enhanced Raman spectroscopy (SERS). Journal of Food Science, 79: T743-747.

Wu, Y., An, Q., Li, D., Wu, J. \& Pan, C. 2019. Comparison of different home/commercial washing strategies for ten typical pesticide residue removal effects in kumquat, spinach and cucumber. International Journal of Environmental Research and Public Health, 16(3): 472.

Yigit, N. \& Velioglu, Y.S. 2020. Effects of processing and storage on pesticide residues in foods. Critical Reviews in Food Science and Nutrition, 60(21): 3622-3641

Zaidon, S.Z., Ho, Y.B., Hashim, Z., Saari, N. \& Praveena, S.M. 2018. Pesticides contamination and analytical methods of determination in environmental matrices in Malaysia and their potential human health effects - A review. Malaysian Journal of Medicine and Health Sciences, 14(101): 81-88. 
